\title{
Importance of the experimental investigation of a concasting technology
}

\author{
Josef Štětina ${ }^{1}$, František Kavička ${ }^{1,}{ }^{*}$, Jaroslav Katolický ${ }^{1}$, Tomáš Mauder ${ }^{1}$, and Lubomír \\ Klimeš ${ }^{1}$ \\ ${ }^{1}$ Brno University of Technology, Faculty of Mechanical Engineering, Czech Republic
}

\begin{abstract}
The solidification and cooling of a continuously cast billet, slab or cylinder, generally of a concasting and the simultaneous heating of the mold is a very complicated problem of three-dimensional (3D) transient heat and mass transfer. The solving of such a problem is impossible without numerical models of the temperature field of the concasting itself which it is being processed through the concasting machine (caster). The application of the numerical model requires systematic experimentation and measurement of operational parameters on a real caster as well as in the laboratory. The measurement results, especially temperatures, serve not only for the verification of the exactness of the model, but mainly for optímization of the process procedure: real process $\rightarrow$ input data $\rightarrow$ numerical analyses $\rightarrow$ optimization $\rightarrow$ correction of real process. The most important part of the investigation is the measurement of the temperatures in the walls of the mold and the surface of the slab in the zones of secondary and tertiary cooling.
\end{abstract}

\section{Introduction}

The production of steels, alloys and metallurgical products in general is constantly developing. Materials with high utility parameters are more in demand and traditional production is being replaced by higher quality steel. More and more sophisticated aggregates using more sophisticated technological procedures are being implemented. In order to maintain competitiveness, diversify production and expand to other markets, it is necessary to monitor technological development.

In the case of concasting, it is not possible to fulfill these requirements without the application of models of all caster processes dependent on thermal-mechanical relationships. The successful application of a numerical model (for example of a steel slab) and its continuous improvement is necessarily conditioned by carrying out demanding experiments and their evaluation [1-3]. The measured parameters serve either as direct input data for the numerical model or they are used for the creation of this input data. This is, for example, the case of determining the heat transfer coefficients beneath the cooling jets that has to be carried out in the laboratory (see below). The range of the measurements carried out and applied was relatively considerable. They can therefore be divided into

\footnotetext{
*Corresponding author: kavicka@,fme.vutbr.cz
} 
experimental research carried out on an operational device (caster) and experimental research carried out in laboratory conditions [4]. Research conducted on the operational device comprises permanent monitoring of the necessary physical and technological quantities during the entire process. Some of them are part of a so-called breakout system. This entails relatively extensive files of values containing individual data as well as time records - for example temperature in the walls of the mould, surface temperatures of the slab in the place of the bend, the pouring temperature, the casting speed, the temperature of the cooling water, etc. Furthermore, other experiments were also conducted for the purposes of research. This includes, for example, measurement of the surface temperatures in other places of the secondary-cooling zone (i.e. the cage), after exiting the cage (in the so-called tertiary-cooling zone) [5] and more.

\section{An original off-line model of the temperature field of the concast steel slab $1530 \times 250 \mathrm{~mm}$ (width $\times$ thickness)}

The 3D model had first been designed as an off-line version and later as an on-line version so that it could work in real time. The numerical model takes into account the temperature field of the entire slab (from the meniscus of the level of the melt in the mould to the cutting torch) using a 3D mesh containing more than a million nodal points.

The solidification and cooling of a concast slab $1530 \times 250 \mathrm{~mm}$ is a global problem of $3 \mathrm{D}$ transient heat and mass transfer. If heat conduction within the heat transfer in this system is decisive, the process is described by the Fourier-Kirchhoff equation. It describes the temperature field of the solidifying slab in all three of its states: at the temperatures above the liquidus (i.e. the melt), within the interval between the liquidus and solidus (i.e. in the mushy zone) and at the temperatures below the solidus (i.e. the solid state). In order to solve these it is convenient to use the explicit numerical method of finite differences. Numerical simulation of the release of latent heats of phase or structural changes is carried out by introducing the enthalpy function dependent on temperature $T$, preferably in the form of enthalpy related to unit volume $H_{v}$. The latent heats are contained here. After the automated generation of the mesh (pre-processing) ties on the entry of the thermophysical material properties of the investigated system, including their dependence on temperature - in the form of tables or using polynomials. They are namely the heat conductivity $k$, the specific heat capacity $c$ and density $\rho$ of the cast metal.

The temperature distribution in the slabs described by the enthalpy balance equation. The simplified equation, suitable for application on radial-casters with a great radius, where only the speed (of the movement of the slab) component $w$ in the z-direction is considered, is:

$$
\frac{\partial H_{v}}{\partial \tau}=k \cdot\left(\frac{\partial^{2} T}{\partial x^{2}}+\frac{\partial^{2} T}{\partial y^{2}}+\frac{\partial^{2} T}{\partial z^{2}}\right)+w \cdot \frac{\partial H_{v}}{\partial z}
$$

Enthalpy $H_{v}$ as a thermodynamic function of temperature must be known for each specific steel. It is dependent on the composition of the steel and on the rate of cooling.

The experiment was conducted on a $1530 \times 250 \mathrm{~mm}$ steel slab, where the pouring conditions were characterised by the temperature in the tundish $\left(1550^{\circ} \mathrm{C}\right)$, the temperature of the liquid $\left(152{ }^{\circ} \mathrm{C}\right)$, and the shift rate of the slab $\left(0.82 \mathrm{~m} \cdot \mathrm{min}^{-1}\right)$. The liquidus and solidus temperatures are derived from the composition of the steel.

The exactness of the presented numerical model depends not only on the spatial and temporal discretization, but also on the accuracy with which the thermophysical properties of the materials of all parts of the system are determined. It also depends on the derivation of boundary conditions, i.e. the values of the heat transfer coefficient on all caster boundaries. 


\section{Experimental measurement for the application of the model of the temperature field of a steel slab $1530 \times 250 \mathrm{~mm}$}

\subsection{Measuring temperatures in the mould (crystallizer) and in the secondary cooling zone}

Figure 1 illustrates the positions of 44 thermo-couples in two lines along all walls of the mould [6] (so called the breakout system). The results of these measurements are indicated in Figure 2, together with the course of the mean value and distribution, and are entered into the numerical model of the mould. Figure 2 shows an example of real immediate temperatures on the mould.

In order to make the model of the temperature field of the mould more accurate and to verify it, it is useful to carry out experimental measurement of the surface temperatures immediately below the mould, i.e. in the area of the retaining rollers. The measurement is carried out using optical pyrometers positioned at the centre of the slab, half-way between the centre and the edge and near the corner (Figure 1). This measurement also makes it possible to assess whether the temperature field is symmetrical along the axis of the crosssection. Figure 3 shows the measurement of the surface temperatures along the large radius in the area of the retaining rollers. The graph illustrates that it is necessary to process the data before it is used, i.e. it is necessary to find a suitable method of filtering. The generally used method of filtering is floating averaging. Its disadvantage is that large deviations are spread along a larger area. The median recursive filter brings the strongest filtration - its output is, for example, usable for the regulation of the secondary cooling. It is possible to consider that interference of the signal from the pyrometer is caused by a quality surface of the slab (scales and solidified casting powder). That is why the maximal values provided by the maximum filter are considered as correct [7].

The experimental temperatures could be used from the breakout system (and not the data from the pyrometers), which, with respect to the densely arranged thermocouples in two horizontal planes (Figure 1) covers the asymmetry better. In order to apply the dynamic model of the temperature field, the investigation of only one half of the slab is sufficient. Figure 3 illustrates the favourable comparison of temperatures measured by three pyrometers with a calculated curve of the surface temperatures of the slab after $4000 \mathrm{~s}$.

In order to make the model of the temperature field more accurate and to verify it, it was necessary to use two permanently installed pyrometers with both measuring the upper surface of the slab along the small radius. The first was installed by Mannesmann Demag already at the stage of starting up the caster. It is positioned just before the unbending point. This pyrometer was originally used for checking the function of the process secondary cooling. During the integration of the on-line model into the system, it is now used for comparing the temperatures calculated by the model with the real ones. Furthermore, it was joined by another pyrometer of the same type at the exit from the cage. This arrangement of both models also includes a processing unit that filters the measured data. This facilitates their utilisation because the software of the temperature model no longer has to deal with the filtering of the signal. The pyrometers measure within the range from 750 to $1200{ }^{\circ} \mathrm{C}$ and in the case of a measurement failure it shows a temperature of $700{ }^{\circ} \mathrm{C}$. The positioning of the pyrometers in the two mentioned points is necessary for the purposes of checking. The temperature of the slab in the point of the first pyrometer at the beginning of the unbending (point) must be higher than the temperature prescribed for this point (i.e. a slab that is too cold must not be straightened out). On the other hand, the temperature at the exit of the cage should be lower than the prescribed temperature. 


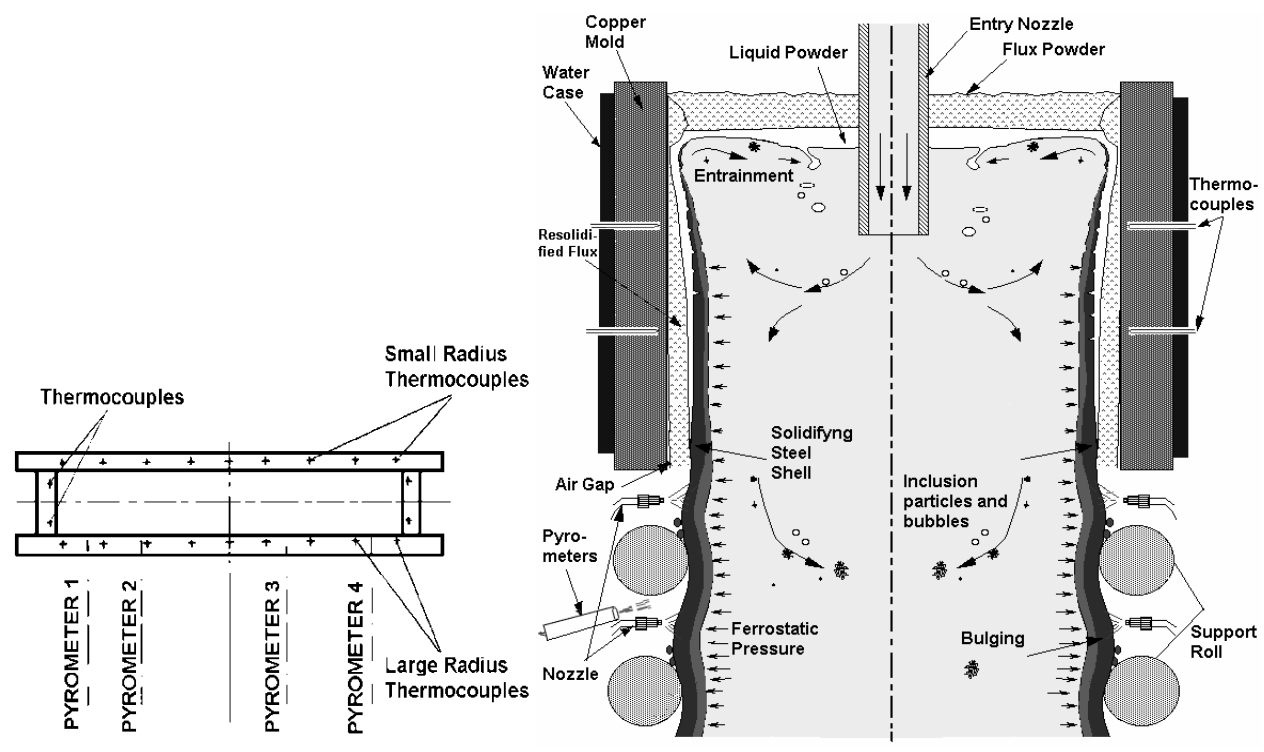

Fig. 1. Arrangement of measurement sensors.

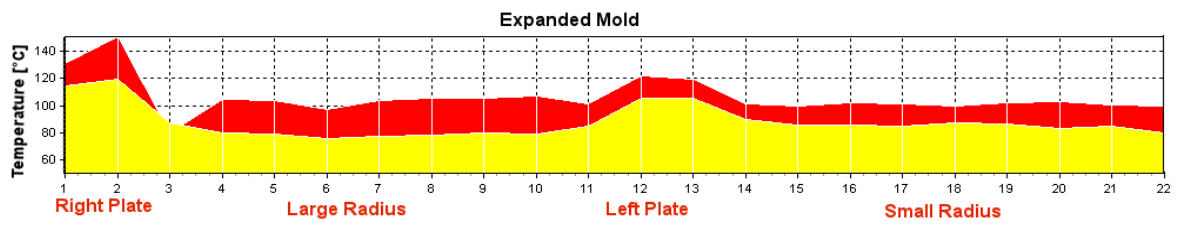

Fig. 2. Immediate temperatures of the breakout system (red - upper line, yellow - bottom line).

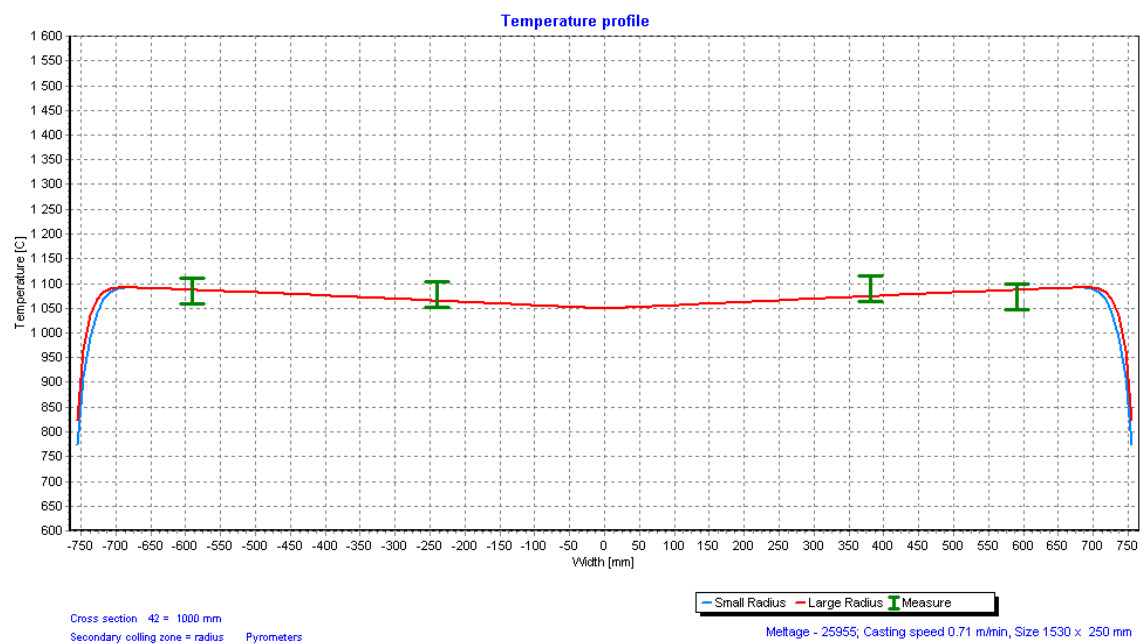

Fig. 3. A comparison of the course of the calculated and measured temperatures after $4000 \mathrm{~s}$.

\subsection{Measuring of cooling effect of nozzles}

A real caster contains a total of 8 types of air-jets and geometrical layouts. Since it is not possible to determine the intensity of the air-water jets on an actual caster, it is necessary to 
transfer the investigation - of each jet individually - to the experimental laboratory device (Figure 4), which is capable of simulating the surface of a concast slab [8-11]. This device also allows the measurement of temperatures beneath the surface within the slab. The temperatures measured are converted to cooling intensities by means of an inverse task, which, in turn, are converted to the courses of the heat transfer coefficients using an expanded numerical model. The numerical model also determines the effect of radiation which is dependent on the surface temperature.

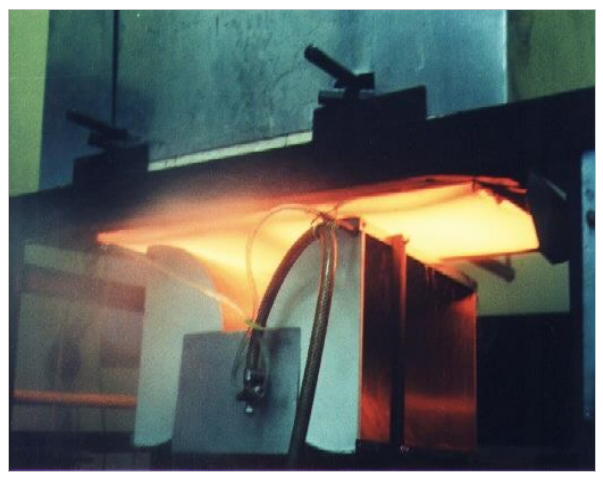

Fig. 4. The laboratory device in use.

\subsection{Measuring of slab surface temperatures in the tertiary cooling zone}

Three $2 \mathrm{~mm}$ insulated thermocouples had been used for the measurement. The hot end of each thermocouple was fixed inside the hollow tip of a stud, carefully positioned on the surface of the slab after cooling (Figure 5) and all were hammered into the same depth during the torch-cutting process [12]. The measurement was initiated on a separated slab, 5to- $6 \mathrm{~m}$ from the exit of the cage, and continued until the slab was cold - in the cooling field. The correction of the error of the measurement result, from the heat transfer through the thermocouple insulation and the protruding end, is conducted via comparison measurements. The measured temperatures of three surface points are in Figure 5.

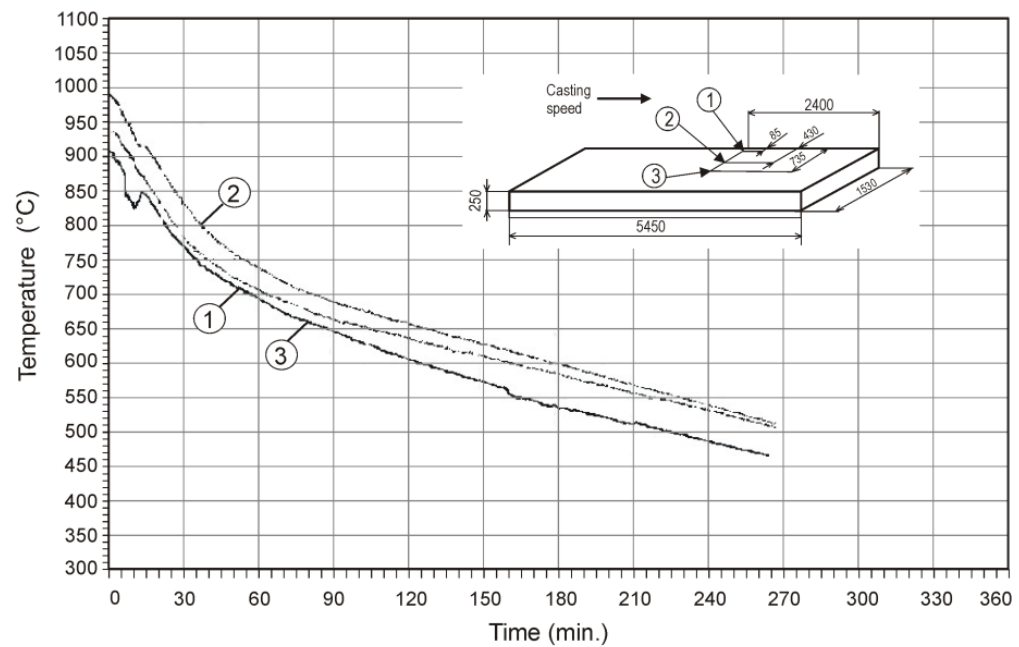

Fig. 5. Temperatures of the three surface points. 


\section{Conclusion}

Research into the thermokinetics of solidification and cooling of concast slabs requires systematic experimental measurement on a real caster. Its results are utilised not only for improving the numerical model of the temperature field but also for assessing the exactness of this model. This dynamic model, which works non-stop in real time, ensures continuous correction of the real process of the caster in question. The main measured quantities are the temperature in the walls of the mould, the surface temperatures of the slab upon exit from the mould, at the unbending point of the slab and upon exit from the cage of the secondary cooling. Furthermore, it is the casting temperature, the casting speed, the temperature of the cooling water, the metallurgical length, etc. A specialised laboratory conducts measurements of the spraying characteristics of individual cooling nozzles. Its output establishes the heat transfer coefficients beneath each of the water or water-air nozzles.

This research was supported through NETME CENTRE PLUS (LO1202) by the Ministry of Education, Youth and Sports of the Czech Republic under the „National Sustainability Programme I“.

\section{References}

1. J.K. Brimacombe, Metall. and Mater. Trans. B, 30B, 553 (1999)

2. J. Miettinen, S. Louhenkilpi, J. Laine, Proc. of Gen. COST 512 Workshop (1996)

3. R.A. Richard, R. Harding, Ch. Beckermann, Metall. \& Mater. Ttransactions, 34B, 297 (2003)

4. J. Štětina, Ph.D. Thesis, TU Ostrava, Czech Rep. (2007)

5. B.G.Thomas, R.J. O’Malley, D.T. Stone, Model. Of Cast. Weld., Solidif. Proc. VIII, San Diego, CA, TMS (1998)

6. F.Kavička, et al., Proc. of $4^{\text {th }}$ Inter. Conf. on Comput. Fluid Dyn. in the Oil, Gas, Metall. and Proc. Ind., Trondheim, Norway (2005)

7. F. Kavička, et al., Communications, 4A2012, 14, 13 (2012)

8. J. Horský, M. Raudenský, Proc. of $14^{\text {th }}$ Inter. Metal. \& Mater. Conf. METAL, Hradec n/M., Czech Rep. (2005)

9. J. Horský, et al., AISTech, Iron\&Steel Techn. Conf. \& exp., Charlotte, USA (2005)

10. M. Raudenský, J. Horský, Ironm. \& Steelm. 32, 2 (2005)

11. J .Štětina, Assoc. professor. \& habilit. thesis, TU Ostrava, Czech Rep. (2008)

12. J. Štětina, et al., Comp. Meth. \& Exp. Meas. XII, 749, WIT Press (2005)

13. F. Kavička et al., Proc. of 5th Pac. Rim Inter. Conf. on Adv. Mater. \& and Proces., Zuerich, Trans Tech Pub. (2004) 